\title{
Biotechnological production and application of fructooligosaccharides
}

\author{
Dulce A. Flores-Maltos ${ }^{1}$, Solange I. Mussatto ${ }^{2}$, Juan C. Contreras-Esquivel ${ }^{1}$, Raúl Rodríguez-Herrera ${ }^{1}$, \\ José A. Teixeira ${ }^{2}$, and Cristóbal N. Aguilar ${ }^{1}$ \\ ${ }^{1}$ Department of Food Science and Technology, School of Chemistry, Universidad Autónoma de Coahuila, Saltillo, Coahuila, México and \\ ${ }^{2}$ Institute for Biotechnology and Bioengineering (IBB), Centre of Biological Engineering, Universidade do Minho, Braga, Portugal
}

\begin{abstract}
Currently, prebiotics are all carbohydrates of relatively short chain length. One important group is the fructooligosaccharides (FOS), a special kind of prebiotic associated to the selective stimulation of the activity of certain groups of colonic bacteria. They have a positive and beneficial effect on intestinal microbiota, reducing the incidence of gastrointestinal infections and also possessing a recognized bifidogenic effect. Traditionally, these prebiotic compounds have been obtained through extraction processes from some plants, as well as through enzymatic hydrolysis of sucrose. However, different fermentative methods have also been proposed for the production of FOS, such as solid-state fermentations utilizing various agroindustrial by-products. By optimizing the culture parameters, FOS yields and productivity can be improved. The use of immobilized enzymes and cells has also been proposed as being an effective and economic method for large-scale production of FOS. This article is an overview of the results considering recent studies on FOS biosynthesis, physicochemical properties, sources, biotechnological production and applications.
\end{abstract}

\section{Keywords}

Fructooligosaccharides, fructosyltransferase, functional foods, inulin, prebiotics

\section{History}

Received 17 June 2013

Revised 19 January 2014

Accepted 1 July 2014

Published online 17 December 2014

\section{Introduction}

Modern nutrition focus on a relationship between food quality and health promotion. For this reason, this discipline is now oriented to provide information on foods with an emphasis in their nutrients and bioactive constituents (García-Casal, 2007). These compounds give additional benefits because of their consumption, conceptualizing them as functional foods, forcing several changes from their manufacture, including nutritional, microbiological, technological and sensorial qualities (García-Casal, 2007).

Bioactive compounds present in functional foods, are mainly phytochemicals with complex and diverse chemical structures, such as carotenoids, isoflavones, cumestans, polyphenols, phytoestanols, conjugated linoleic acid and epigallocatechin gallate (EGCG), among thousands of chemical compounds with beneficial biological activity (AlvídrezMorales et al., 2002). There is significant evidence for a reduction of health risks due to regular consumption of these bioactive compounds, including cardiovascular diseases, cancer, osteoporosis, hyperlipidemia and neurodegeneration (Alvídrez-Morales et al., 2002).

Although, there is not universal consensus about the term of functional food, it is applied to those foods with one or

Address for correspondence: Professor Cristobal N. Aguilar, PhD, Department of Food Science and Technology, School of Chemistry, Universidad Autónoma de Coahuila, 25280, Saltillo, Coahuila, México. E-mail: cristobal.aguilar@uadec.edu.mx more bioactive components which satisfactorily demonstrate a benefit in one or more determined functions of the organism (Mussatto \& Mancilha, 2007). The fundamental effects of functional foods are excellent alternatives to improve health condition and well-being and/or to reduce the risk of some diseases (Mussatto \& Mancilha, 2007). A functional food must be a food primarily and must demonstrate its effects in amounts that normally are consumed in the diet. Within the ample context of functional foods, prebiotics have been intensely studied, due to their diversity and magnitude of beneficial effects on health that their consumption generates (Sabater-Molina et al., 2009).

\section{Prebiotics}

The concept of prebiotics was introduced by Gibson \& Roberfroid in 1995 with a slightly alternative approach which consists of regulation of the gut microbiota (Gibson \& Roberfroid, 1995). At present according to the FAO and several researchers, "a prebiotic is a selectively fermented ingredient that allows specific changes, both in the composition and/or activity in the gastrointestinal microbiota that confers benefits upon host wellbeing and health"' (Al-Sheraji et al., 2013; Charalampopoulos \& Rastall, 2012; Dominguez et al., 2013; Gibson et al., 2004, 2010; Pineiro et al., 2008; Sarbini \& Rastall, 2011; Slavin, 2013; Walton et al., 2013).

These compounds are the trophic substrate of probiotics, generally as a strategy to improve balance, growth and activity of the various kinds of intestinal bacteria including bacteria of the colon (Dominguez et al., 2013; 
Gibson et al., 2004; Macfarlane et al., 2008; Sarmiento Rubiano, 2006; Silveira Rodríguez et al., 2003).

Thus, to be a nutritional ingredient classified as prebiotic, it must fulfill the following requirements: a) low sensibility to hydrolysis by saliva, pancreatic and intestinal enzymes or absorption along the gastrointestinal tract; b) constitute a fermentable substrate for the intestinal microflora as established by scientific studies as are: inulin, fructooligosaccharides (FOS), galactooligosaccharides (GOS), isomaltooligosaccharides (IMO), xylooligosaccharides (XOS) and soybean oligosaccharides (SOS) and to selectively stimulate growth and metabolism of one or more beneficial bacteria to the colon c) to modify the composition of the colon flora, facilitating development of beneficial species, and d) to induce beneficial effects into the lumen or are systemically relevant for the health of the individuals (Charalampopoulos \& Rastall, 2012; Dominguez et al., 2013; Gibson, 1999; Scheid et al., 2013; Slavin, 2013).

Non-digestible carbohydrates (oligosaccharides and polysaccharides), some peptides and proteins, and certain lipids (esters and ethers) are considered to be prebiotics. Due to their chemical structure, these compounds are not absorbed into the gastrointestinal tract and are not hydrolyzed by human digestive enzymes due to their configuration $\beta$ in $C_{2}$ (Gibson et al., 2004). These compounds can be named colon foods, since they enter into the colon where they are released, allowing their absorption. Moreover, the short-chain carbohydrates increase colonic absorption of zinc, calcium and magnesium ions when causing water attraction by osmosis, in which such minerals are dissolved, providing energy, metabolic substrates and essential micronutrients to the organism (Pérez Conesa et al., 2004; Roberfroid et al., 1998, Silveira Rodríguez et al., 2003).

Carbohydrates can be classified according to their degree of polymerization in oligosaccharides (between 2 and 10 units of monosaccharides) and polysaccharides (more than 10 monosaccharides) as indicated by IUB-IUPAC terminology (Nomenclature, 1982). Englyst \& Hudson (1996) proposed the name of short chain carbohydrate for a new nutritional carbohydrate group that included oligosaccharides and the smallest polysaccharides. The main available oligosaccharides are carbohydrates in which the monosaccharidic unit is fructose, galactose, glucose, and/or xylose (Crittenden \& Playne, 1996; Delzenne \& Roberfroid, 1994), including in this important group the FOS.

\section{Fructooligosaccharides (FOS)}

FOS are non-digestible carbohydrates that represent one of the major classes of bifidogenic oligosaccharides, FOS is the common name for fructose oligomers, chemically composed mainly of chains of fructose units with a terminal glucose molecule unit linked by glycosidic bridges $\beta$-(2-1) (ChacónVillalobos, 2006; Monsan \& Ouarné, 2009; Sabater-Molina et al., 2009). Also, they are known as fructans, oligofructans, glucofructans, inulins or oligosaccharides, where their structure is formed by repetitive unions of disaccharides such as sucrose, inulobiose and levanobiose (Chacón-Villalobos, 2006). FOS are reserve phytochemicals present in many plants and vegetables as reserve carbohydrates such as
Jerusalem artichoke, onion, asparagus, chicory, leek, garlic, wheat, yacon, tomatoes, banana and honey (Monsan \& Ouarné, 2009; Mussatto et al., 2009a). According to their structural differences, there are four important groups of FOS: inulin, levan, mixed levan and neo- FOS (Monsan \& Ouarné, 2009).

Inulin is a fructooligosaccharide with a polymerization degree of 2 to 60 monomers of fructose (Murphy, 2001; Roberfroid, 2007b; Watzl et al., 2005). It has been defined as polydisperse fructans, constituted mainly, but not exclusively, of $\beta$-(1-2)-fructofuranosyl linkages. Inulin can be obtained from several plant families (mono and dicotyledonous). Nevertheless, only chicory (Chicorium intybus) is used to produce inulin at the industrial level, this process is similar to that used for sugar production from sugar beet. Native inulin is processed and transformed into FOS or short chain fructans (scFOS) with a degree of polymerization between 2 and 10 (normally 5) as a result of partial enzymatic hydrolysis with inulinase (Gibson \& Rastall, 2006).

Oligofructose is chemically defined as linear non-digestible oligosaccharide of $\beta$-(2-1)-linked fructose fraction with a terminal glucose residue unit of oligosaccharides with a degree of polymerization between 2 and 20. Due to the structural conformation of their osidic bridge (3 2-1), this resists the hydrolysis by human alimentary enzymes (Roberfroid, 1993). Oligofructose is the strict definition to oligosaccharides obtained naturally from the enzymatic hydrolysis of inulin that can otherwise be obtained by enzymatic synthesis (transfructosylation) using sucrose as a substrate and consists of a mixture of fructosyl chains (maximum of 5 units), with terminal glucose and fructose FOS of short chain (Roberfroid, 2002, 2007a, Venter, 2007; Walton et al., 2013; Watzl et al., 2005).

Short chain FOS (scFOS) are a mixture of oligosaccharides containing of glucose linked to fructose units: bonds between fructose units are $\beta$ (2-1) forming the fructooligosaccharides: 1-kestose, nystose and 1-fructofuranosyl-nystose (Figure 1; Roberfroid \& Delzenne, 1998; Sánchez et al., 2008; Vega \& Zuniga-Hansen, 2014). Kestose is formed by addition of a fructose molecule to one of sucrose. Nystose is formed by the later addition of a fructose molecule, while the addition of another molecule of fructose will give rise to the formation of fructofuranosyl-nystose (Dorta et al., 2006; Rivero-Urgell \& Santamaria-Orleans, 2001).

Depending on the linkage type between the monosaccharide residues, different types of FOS series can be distinguished. Neo-FOS consists mainly of neo-kestose (neo- $\left.\mathrm{GF}_{2}\right)$ and neo-nystose $\left(\right.$ neo- $\left.\mathrm{GF}_{3}\right)$, in which fructosyl units are $\beta$-(2-6)-linked to the fructofuranosyl residue of sucrose (Chen et al., 2011; Kilian et al., 2002; Lim et al., 2007; Linde et al., 2012; Park et al., 2005; Plou Gasca et al., 2009). However, neo-FOS have not been widely explored, probably because they are not produced by fructofuranosidases in microorganisms (Álvaro-Benito et al., 2007; Chen et al., 2011; Ghazi et al., 2007) or they represent only a minor biosynthetic product (Chen et al., 2011; Farine et al., 2001).

\section{Physico-chemical properties of FOS}

FOS are compounds soluble in water and their sweetness oscillates between 0 , and 6 times to that of sucrose, having the 
(a)

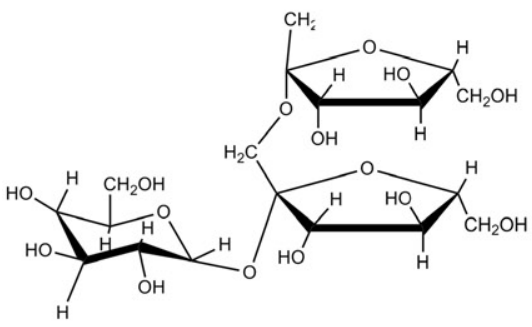

(b)

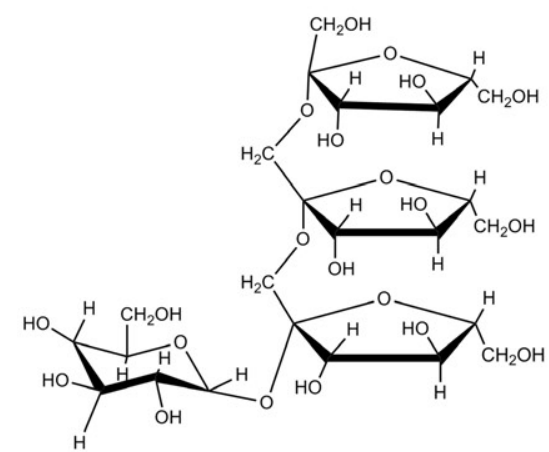

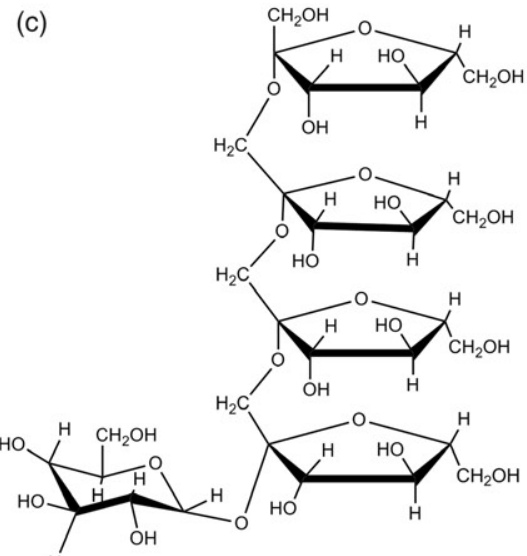

Figure 1. Chemical structures of the most important fructooligosaccharides, (a) 1-kestose, (b) nystose and (c) 1-fructofuranosyl-nystose.

chemical structure and degree of polymerization of oligosaccharides (Alméciga-Díaz et al., 2011; Crittenden \& Playne, 1996; Yun, 1996). The sweetness decreases with longer the oligosaccharide chain length. This low sweetness intensity is quite useful in the various kinds of foods, where the use of sucrose is restricted by its high sweetness property (Roberfroid \& Slavin, 2000).

There is a considerable amount of information on the stability of prebiotics, in particular of FOS mainly from experiments using model systems and to a lesser extent with real foods (Charalampopoulos \& Rastall, 2012). FOS has been thought to be less stable than other oligosaccharides in conditions of low $\mathrm{pH}$ and high temperature, especially the combination of the two. In very acidic conditions, the $\beta-(2-1)$ bonds between the fructose units can be partially hydrolyzed (Bosscher, 2009; Charalampopoulos \& Rastall, 2012).

Suggested further work is the evaluation of the stability of prebiotics in real food systems rather than model solutions, as there is a lack of data on this and the scarce existing data suggest that the food matrix can influence prebiotic stability.

FOS are highly hygroscopic and their water retention capacity is major to that of sucrose and equal to that of sorbitol (Bornet, 1994; Yun, 1996). Thus, it is difficult to maintain the stable freeze-dried product under atmospheric conditions during prolonged storage periods.

\section{Prebiotic effect of FOS}

In the last decades, the effect of bacterial microflora on human health has been one of the main research topics. The large intestine contains more than 500 different types of bacteria, which contribute to an important number of biological functions. Recent studies in vivo and in vitro with Bifodobacterium longum, B. infantis and B. angulatum revealed an important growth increase when FOS were used as a carbon source (Cummings et al., 2001; Rastall \& Maitin, 2002). It was also observed that consumption of FOS decreases populations of Clostridium and reduces production of flatulences (Cummings et al., 2001; Rastall \& Maitin, 2002). After comparing healthy humans with daily ingestion of low doses of FOS $(5-20 \mathrm{~g} / \mathrm{d})$ against placebos with high amounts of sucrose, it was found that bifidobacteria increased in order of magnitude above of the normal microbial accounts (Cummings et al., 2001; Macfarlane et al., 2006; Reyed, 2007).
During fermentation, prebiotics can promote some specific physiological functions through liberation of metabolites, especially short chain fatty acids (acetate, propionate, butyrate, lactate, etc.) to the intestinal lumen (Olvera et al., 2007b). Short chain fatty acids may act directly or indirectly on intestinal cells and can participate in control of several processes like mucosal proliferation, inflammation, colorectal carcinogenesis, mineral absorption and nitrogen compounds elimination. This FOS property is recognized in several European countries and named as the prebiotic effect. Among the FOS clearly identified with this beneficial effect are kestose and neokestose (Gibson \& Rastall, 2006).

\section{Biotechnological production of FOS}

Currently, the main route of chemical synthesis of glycosylated compounds is unattractive due to high chemical sensitive of sugars, which consequently brings the necessity of protection and lack of protection of substrates and products (Tomotani \& Vitolo, 2007). In addition, most of the used chemical catalysts are toxic with low specificity, which limits their application in the pharmaceutical and food industries (Tomotani \& Vitolo, 2007). Alternatively, the increasing presence of biocatalysis in different processes of chemical synthesis has opened the possibility to develop selective, efficient and less aggressive alternative processes (Nemukula et al., 2009).

FOS are produced by transfructosylation of sucrose which is carried out via the breaking of the $\beta$-(2-1)-glycosidic bond and the transfer of the fructosyl moiety onto any acceptor other than water, such as sucrose or a fructooligosaccharide. In the enzymatic synthesis of FOS, microbial enzymes with transfructosilase activity should be utilized. This synthesis is a complex process in which several reactions occur simultaneously, both in parallel and in series, because FOS are also potential substrates of fructosyltransferases (FTases) (Vega \& Zuniga-Hansen, 2014). These enzymes are usually classified as $\beta$-D-fructofuranosidases (FFase, EC 3.2.1.26), with high transfructosylating activity or fructosyltransferase (FTase, EC 2.4.1.9) (Maiorano et al., 2008b). These enzymes may be produced intra and extracellular by several microorganisms, including bacteria and fungi, as shown in Table 1. Fructofuranosidases production may occur by two kinds of processes: submerged fermentation $(\mathrm{SmF})$ and solid-state 
fermentation (SSF). Most research studies on the experimental conditions for FTase production have been conducted under submerged fermentation conditions, being mainly based on shake-flask experiments with some fungal strains. Fermentation parameters such as culture medium, aeration, agitation, $\mathrm{pH}$ and temperature must be established for each microorganism, but general conditions for the enzyme production are well known.

Most enzymes for industrial use are produced by SmF but the growing trend of using SSF represents a great alternative to small-scale occurring extracellular. Some advantages of SSF processes are: high volumetric productivity and enzyme concentration, low production costs and energy consumption, the risk of contamination is minimal but the most important are more stable products (Balasubramaniem et al., 2001; Longo et al., 2008; Sangeetha et al., 2004).

Various agro industrial by-products are considered good substrates in SSF processes, especially for enzymes production (Graminha et al., 2008; Rodríguez Couto \& Sanromán, 2005). Some of these substrates include cereal brans, sugarcane bagasse, wheat straw, rice husk, soybean shell, corn cobs, cassava waste, apple pomace and waste from tea and coffee industries (Sangeetha et al., 2004). There are many reports on FTase production using SmF and very few using SSF (Sangeetha et al., 2004). Table 2 summarizes some studies using SSF with agro-industrial wastes for the production of FTase.

SSF is defined as the cultivation of microorganisms on wet or semi-moistened solid media (Botella et al., 2007; Lateef et al., 2008b), supports can be inert and insoluble or substrates that can be used as a carbon and energy source (Rodríguez Couto \& Sanromán, 2005). SSF is carried out in the absence or with minimum amount of free water trying to adapt the culture conditions of each microorganism (Rodríguez Couto \& Sanromán, 2005). SSF is used to produce various chemicals and enzymes. This technique has

Table 1. Microorganisms that produce FTase.

\begin{tabular}{ll}
\hline Microorganism & Reference \\
\hline Aspergillus japonicus JN19 & (Wang \& Zhou, 2006) \\
Aspergillus oryzae CRF 202 & (Sangeetha et al., 2004) \\
Rhizopus stolonifer LAU07 & (Lateef et al., 2008a) \\
Rhodotorula sp & (Hernalsteens \& Maugeri, 2008) \\
Aspergillus japonicus ATCC 20236 & (Mussatto et al., 2009b) \\
Rhodotorula dairenensis & (Gutiérrez-Alonso et al., 2009) \\
Penicillium expansum & (Prata et al., 2010) \\
Penicillium purpurogenum & (Dhake \& Patil, 2007) \\
Aspergillus phoenicis & (Rustiguel et al., 2011) \\
\hline
\end{tabular}

several advantages such as more stable products and in high concentration, low catabolic repression, and aeration easy, requiring little energy production fermenters which can be used on small and large scale thereby decreasing pollution effluents (Hölker et al., 2004; Longo et al., 2008). Another advantage is that SSF is developed under low moisture content, which is a limitation for several microorganisms. Therefore, this kind of fermentation can be performed mainly by some fungi and yeast, and seldom by bacteria (Hölker et al., 2004; Longo et al., 2008). In addition, using SSF has the possibility of using mixed cultures and thereby exploit the synergism of metabolism between the microorganisms (Hölker et al., 2004).

Generally, the FTase is obtained by liquid or solid fermentation liquid and is used for production of FOS. However, new processes such as fermentation with biofilms have been developed to produce biotechnologically important molecules, combining the advantages of the solid fermentation and high productivity (Aziani et al., 2012). The growth of filamentous fungi in their natural environment is given by the direct association with the substrate, which is extremely important as this allows adhesion and spore germination to form mycelium (Aziani et al., 2012).

There are reports of FOS production by colonization of Aspergillus japonicus in synthetic media (Mussatto et al., 2009a). Colonization occurred in the holder during fermentation, and thus the production of FOS is influenced by the metabolic action of free and immobilized cells. Aziani et al. (2012) immobilized cells in an aqueous solution and not in the culture medium for the production of FOS (Aziani et al., 2012). This procedure has several advantages among which stands out the separation of the cells, recovery of products (FOS) of the fermentation broth and reuse of the catalysts (biofilm) employed for the production of FOS can reduce process costs (Aziani et al., 2012).

FTases are enzymes with potential to be used during the glycosylation process of molecules. Bacterial FTases generally have molecular weights between 45 and $64 \mathrm{kDa}$, although those produced by lactic acid bacteria usually have superior molecular weights (from 80 to $170 \mathrm{kDa}$ ) (Olvera et al., 2007a). Most of these enzymes are extracellular, i.e. they are secreted into the culture medium during the growth of bacteria. The fungal FTases have molecular weights between 60 and $75 \mathrm{kDa}$, although other enzymes with a higher molecular weight have also been reported (Maiorano et al., 2008a). In both fungal and plants FTases, six conserved regions are clear, in three of these are located the possible amino acids implied on catalysis. One of these regions allows

Table 2. Agro-industrial residues used as substrates in SSF for the production of FTase.

\begin{tabular}{lll}
\hline Microorganism & Substrate & Reference \\
\hline $\begin{array}{l}\text { A. foetidus NRRL 337 } \\
\text { A. niger NRRL 330 }\end{array}$ & Commercial apple pomace & (Hang et al., 1995) \\
A. oryzae CFR 202 & Sugarcane bagasse & (Balasubramaniem et al., 2001) \\
& Cereal brans like wheat bran, rice bran and oat bran; Corn products & (Sangeetha et al., 2004) \\
& $\begin{array}{l}\text { like corn cob, corn bran, corn germ, corn meal, corn grits and whole } \\
\text { corn powder (coarse); Coffee- and tea-processing by-products like }\end{array}$ & \\
coffee husk, coffee pulp, spent coffee and spent tea; Sugarcane & \\
A. japonicus ATCC 20236 & Cagasse, Cassava bagasse (tippi). & (Mussatto et al., 2009b) \\
Rhizopus stolonifer LAU07 & Cassava wastes & (Lateef \& Gueguim Kana, 2012) \\
\hline
\end{tabular}


the enzyme to be bound to sucrose (Kurakake et al., 2007). Because of the structural similarity between fungal and plant FTases, and that these enzymes hydrolyze sucrose (invertase) and other fructosides, they are classified within the 32 family of glycoside hydrolases (Wallis et al., 1997).

The properties of the microbial FTases may vary according to the microorganism and culture medium composition; specifically the carbon source may act as an inducer (Maiorano et al., 2008a). FOS are produced by the action of microbial and plant transfructosyltransferases (Sánchez et al., 2010), by two processes, generating products slightly different end products. In the first method, FOSs are obtained from the disaccharide sucrose using the activity of transfructosylation of the fungal fructosyltransferase enzyme (Park \& Almeida, 1991). The FOS thus formed contains from 2 to 4 units of the fructose bond with connections $\beta(2 \rightarrow 1)$, a terminal remainder to-D-glucose, and among them it is possible to emphasize: 1-kestose (Glu-Fru2), 1-nystose (GluFru3) and 1-fructosylnystose (Glu-Fru4). The second method is controlling the enzymatic or chemical hydrolysis of inulin. In this case, all fructosyl chains $\beta$ (2-1) do not finish in a terminal glucose and the produced oligosaccharides mixture contains chains of fructo-oligomers longer than those produced by the process of sucrose transfructosylation (Crittenden \& Playne, 1996). This product is known as oligo-fructose (Crittenden \& Playne, 1996).

In presence of sucrose, reaction conditions and substrate concentrations, FTases are able to carry out several reactions. They can synthesize a polymer, transferring fructose to the growing chains or hydrolyze it to sucrose (Antošová et al., 2002; Maiorano et al., 2008a; Olvera et al., 2007b). When an outside molecule is added to the reaction medium, this molecule is called an acceptor, the enzyme may also transfer fructose, producing a fructosylated molecule also called a fructoside. An interesting mechanism regarding the reaction of these enzymes was proposed by Chambert et al. (1974). They suggested, from kinetic studies on initial velocity, that the behavior is of the Ping-Pong BiBi type (Figure 2). In this behavior, it is proposed that enzyme and sucrose form an enzyme-fructose intermediary (Ping), and the glucose is released (Pong). This complex interacts, for example, with a water molecule (Ping), and fructose is then transferred releasing a second product - fructose (Pong). This second product can be the growing chain of fructoses or only a fructoside (Olvera et al., 2007b; Vega \& Zuniga-Hansen, 2014).

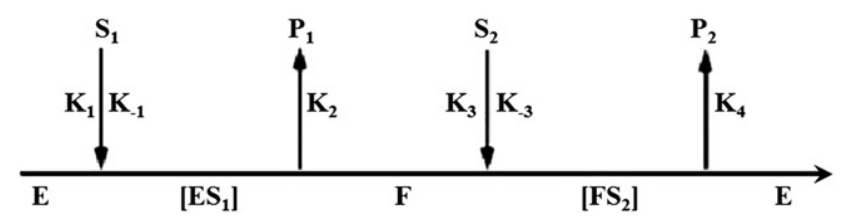

Figure 2. Mechanism of reaction type "Ping-pong Bi-Bi". E is concentration of free enzyme; $S_{1}$ and $S_{2}$ are concentrations of the first and the second substrates, respectively; $\mathrm{ES}_{1}$ represents binary complex (enzyme-substrate); $\mathrm{FS}_{2}$ is for binary complex; $\mathrm{P}_{1}$ and $\mathrm{P}_{2}$ are the first and the second products of enzymatic reaction, respectively; $\mathrm{K}_{1} ; \mathrm{K}_{2} ; \mathrm{K}_{3}$ $\mathrm{K}_{4}$; and $\mathrm{K}_{1} ; \mathrm{K}_{-3}$ are rate constants of forward and reverse reactions, respectively.
The biochemical mechanism used by these fructosylases occurs in two steps: the sucrose (glucose-fructose) enters to the active site where it interacts and a covalent bond between fructose and the enzyme is formed. It is known that this connection is with aspartic 86 , being in this way that the enzyme unites covalently to fructose. In the second step, a new sucrose molecule is recognized at the active site, the site that was occupied before by glucose: fructoses together with D86 then are transferred. Aspartic 247 is used to stabilize the state of transition between these two steps (Kim et al., 1996).

Recent research on industrial enzymology has succeeded in producing large-scale FOS by enzymatic processes. Industrial processes for FOS production can be divided into two classes: a batch system using free enzyme and the second a continuous system with immobilized enzyme or cells.

Immobilization of enzymes for use in reactors allows for a high-enzyme load with high activity within the bioreactor, hence leading to high-volumetric productivities. This enables control of the extension of the reaction. Downstream processing is simplified, since the biocatalyst is easily recovered and reused. The product stream is with a biocatalyst where continuous operation and process automation are employed and substrate inhibition can be minimized. Along with this, immobilization prevents enzyme denaturation by autolysis or organic solvents, and can bring enhance thermal, operational and storage stabilization, provided the immobilization is adequately designed (Fernandes, 2010; Mateo et al., 2007; Sheldon, 2007).

Immobilization can be performed by several methods, namely, entrapment or microencapsulation, binding to a solid carrier, and cross-linking of enzyme aggregates, resulting in carrier-free macromolecules (Fernandes, 2010; Sheldon, 2007). For the large-scale production of FOS, $\beta$-fructofuranosidase has been immobilized on porous glass, porous silica (Hayashi et al., 1991, 1992, 1993) and ion-exchange resins (Yun \& Song, 1996), gluten (Chien et al., 2001), polymethacrylate (Ghazi et al., 2005), macroporous beads (Tanriseven \& Aslan, 2005), calcium alginate (Jung et al., 2011; Lin \& Lee, 2008; Sheu et al., 2013; Yun et al., 1990), amberlite (Csanadi \& Sisak, 2008), niobium and graphite (AlvaradoHuallanco \& Maugeri-Filho, 2010). The immobilization of the FTase offers a lot of practical advantages, e.g. the easy separation of enzyme and product, the opportunity to realize a continuous process, the enhancement of volumetric productivity of the reactor, more stability to changes in $\mathrm{pH}$ and temperature than free FTase and increased operational stability.

Recent processes for FOS production are shown in Table 3 where it is compared to the batch and processes used to yield FOS production. The Company Meiji Seika began the industrial production of FOS from Aspergillus niger cells immobilized in calcium alginate and recently the company Cheil Food and Chemicals (Seoul Korea) developed a continuous process with immobilized cells of Aspergillus pullulan in a calcium alginate gel.

\section{FOS applications in the food industry}

In food industries, because chemical additives are becoming less and less welcome by consumers, there is an increasing 
Table 3. Studies on the production of FTase by different processes.

\begin{tabular}{lclcl}
\hline Enzyme source & Sucrose (g/L) & \multicolumn{1}{c}{ Process* } & FOS yield (\% w/w) & \multicolumn{1}{c}{ Authors } \\
\hline A. pullulans & 770 & Semi-batch (IC) & $55-57$ & (Yun et al., 1990) \\
Aureobasidium sp. & 400 & Continuous (IE) & 2.3 & (Hayashi et al., 1991) \\
A. phoenicis & 750 & Batch (M) & 40 & (Balken et al., 1991) \\
Aureobasidium sp. & 400 & Column reactor (IE) & 37.5 & (Hayashi et al., 1992) \\
A. pullulans & 600 & Column reactor (IC,IE) & 46 & (Yun \& Song, 1996) \\
A. pullulans \& A. niger & 700 & Batch (M) & 67 & (Madlová et al., 2000) \\
A. japonicus & 400 & Column reactor (IC) & 61 & (Chien et al., 2001) \\
A. aculeatus \& A. niger & 630 & Batch (IE) & 61.42 & (Ghazi et al., 2005) \\
Pectinex Ultra SP-L & 600 & Batch (IE) & 57.2 & (Tanriseven \& Aslan, 2005) \\
A. oryzae CFR & 600 & Batch (M) & 53 & (Sangeetha et al., 2005) \\
Aspergillus sp N74 & 700 & Airlift reactor (M) & 69 & (Sánchez et al., 2008) \\
A. japonicus \& A. niger & 300 & Airlift reactor (IC) & 55 & (Lin \& Lee, 2008) \\
Rhodotorula sp. & 50 & Batch (FE) & 48 & (Hernalsteens \& Maugeri, 2008) \\
A. pullulans & 400 & Batch (FE) & 62 & (Yoshikawa et al., 2008) \\
A. japonicus & 200 & Batch (IC) & $64-69$ & (Mussatto et al., 2009b) \\
A. pullulans & 770 & Continuous (IC) & 23.37 & (Jung et al., 2011) \\
Penicillium expansum & 200 & Batch (IC) & $52-60$ & (Mussatto et al., 2012) \\
Rhizopus stolonifer LAU07 & 600 & Batch (IC) & 34 & (Lateef \& Gueguim Kana, 2012)_ENREF_26_ENREF_26 \\
A. japonicus \& Pichia heimii & 300 & Continuous (IC) & 62 & (Sheu et al., 2013) \\
\hline
\end{tabular}

*IC, IE, FE and M indicate immobilized cells, immobilized enzyme, free enzyme and intact mycelium, respectively.

interest in the use of saccharidic natural substances known as prebiotic and bio-preservative FOS (Barreteau et al., 2006). The term biopreservative includes a wide range of natural products from both plants and microorganisms, which are able to extend the shelf life of foods, reduce or eliminate pathogenic microorganisms and increase the overall quality of food products. These natural occurring antimicrobials can be, for example, peptides such as bacteriocins or lipophilic substances such as essential oils (Cleveland et al., 2001). Compared to these two kinds of antimicrobial molecules, sugar molecules seem to be less investigated as potential food preservatives (Barreteau et al., 2006). Different functional properties of FOS are due to the difference in their chain lengths. FOS contribute to give body to dairy products and humectancy to soft baked products, decreases the freezing point in frozen desserts, provides crispness to low fat cookies and acts as a binder in nutritional or granola bars in much of the same way as sugar, but with the added benefit of fewer calories, fiber enrichment and other nutritional properties (Kaur \& Gupta, 2002). Industries producing FOS commercially from the transfructosylation of sucrose or inulin hydrolysis are listed in Table 4.

\section{Concluding remarks}

It is important to emphasize that many research groups have indicated that deficiencies in the diet can lead to disorders and diseases, which can be avoided through an adequate intake of relevant dietary nutrients and functional molecules. FOS are generally used as Generally Recognized As Safe (GRAS) components of functional foods and play a key role in the improvement of the gut microbiota balance and in individual health. For this reason, recently, a great interest on FOS and their influence on dietary modulation (including moderate sweetness, low carcinogenicity, low calorimetric value, and low glycemic index, etc.) of the human gut has been registered.

During the last years, developing products with prebiotic effects has been in the spotlight, and these new products include FOS obtained from sucrose or inulin. FOS have an
Table 4. The companies that commercially manufacture FOS (Alméciga-Díaz et al., 2011; Mussatto et al., 2012).

\begin{tabular}{lll}
\hline Substrate & \multicolumn{1}{c}{ Manufacturer } & \multicolumn{1}{c}{ Trade name } \\
\hline Sucrose & Beghin-Meiji Industries, Marckolsheim, & Actilight \\
& France & \\
& Cheil Foods and Chemicals Inc., Seoul, & Oligo-Sugar \\
& South Korea & \\
& GTC Nutrition, CO, USA & NutraFlora \\
& Meiji Seika Kaisha Ltd., Tokyo, Japan & Meioligo \\
& Victory Biology Engineering & Prebiovis scFOS \\
& Co., Ltd., Shenzhen, Guangdong, & \\
& China & \\
Inulin & Orafti Active Food Ingredients, NJ, USA & Raftilose \\
& Beneo-Orafti, Oreye, Belgium & Orafti \\
& Cosucra Groupe, Warcoing, Belgium & Fibrulose \\
& Jarrow Formulas, LA, USA & Inulin FOS \\
\hline
\end{tabular}

important economic role in view of the high demand for obtaining and producing quickly on a large scale and at low costs. Conventionally, they are produced through a two-stage process that require an enzyme production and purification step in order to proceed with the chemical reaction itself. Several studies have been conducted on the production of FOS, aimed at optimizing the development of more efficient production processes and their potential as food ingredients. The improvement of FOS yield and productivity can be achieved by the use of different fermentative methods and different microbial sources of FOS-producing enzymes and the optimization of nutritional and culture parameters. Therefore, this review focuses on the latest progress in FOS research such as its production, functional properties, and market data. This is why biotechnology is developing new processes capable of increasing industrial production of enzymes associated in the production of FOS, as there are few investigations related to the production of these enzymes in large scale bioreactors. Therefore, studies have been focused on establishing biochemistry parameters and biochemical engineering in order to improve the production process as well as its economic viability. 


\section{Declaration of interest}

The authors thank the National Council of Science and Technology of Mexico (CONACYT) for funding this study. D. A. Flores-Maltos thank the CONACYT for the financial support provided for her postgraduate studies in the Food Science and Technology Program, Universidad Autónoma de Coahuila, Mexico.

\section{References}

Alméciga-Díaz CJ, Gutierrez ÁM, Bahamon I, et al. (2011). Computational analysis of the fructosyltransferase enzymes in plants, fungi and bacteria. Gene, 484, 26-34.

Al-Sheraji SH, Ismail A, Manap MY, et al. (2013). Prebiotics as functional foods: a review. J Funct Foods, 5, 1542-53.

Alvarado-Huallanco MB, Maugeri-filho F. (2010). Kinetics and modeling of fructo-oligosaccharide synthesis by immobilized fructosyltransferase from Rhodotorula sp. J Chem Technol Biotechnol, 85, $1654-62$.

Álvaro-Benito M, De Abreu M, Fernández-Arrojo L, et al. (2007). Characterization of a $\beta$-fructofuranosidase from Schwanniomyces occidentalis with transfructosylating activity yielding the prebiotic 6-kestose. J Biotechnol, 132, 75-81.

Alvídrez-Morales A, González-martínez BE, Jiménez-Salas Z. (2002). Tendencias en la producción de alimentos: alimentos funcionales. Revista Salud Pública y Nutrición. Medigraphic - Literatura Biomédica.

Antošová M, Polakovič M, Slovinská M, et al. (2002). Effect of sucrose concentration and cultivation time on batch production of fructosyltransferase by Aureobasidium pullulans CCY 27-1-1194. Chem Papers, 56, 394-9.

Aziani G, Terenzi HF, Jorge JA, Guimarães LHS. (2012). Production of fructooligosaccharides by Aspergillus phoenicis biofilm on polyethylene as inert support. Food Technol Biotechnol, 50, 40-5.

Balasubramaniem AK, Nagarajan KV, Paramasamy G. (2001). Optimization of media for $\beta$-fructofuranosidase production by Aspergillus niger in submerged and solid state fermentation. Process Biochem, 36, 1241-7.

Balken JAM, Dooren TJGM, Tweel WJJ, et al. (1991). Production of 1-kestose with intact mycelium of Aspergillus phoenicis containing sucrose-1F-fructosyltransferase. Appl Microbiol Biotechnol, 35, 216-21.

Barreteau H, Delattre C, Michaud P. (2006). Production of oligosaccharides as promising new food additive generation. Food Technol Biotechnol, 44, 323-33.

Bornet F. (1994). Undigestible sugars in food products. Am J Clin Nutr, 59, 763S-9S.

Bosscher D. (2009). Fructan prebiotics derived from inulin. In: Charalampopoulos D, Rastall R, eds. Prebiotics and probiotics science and technology. New York: Springer, 163-205.

Botella C, Diaz A, De Ory I, et al. (2007). Xylanase and pectinase production by Aspergillus awamori on grape pomace in solid state fermentation. Process Biochem, 42, 98-101.

Chacón-Villalobos A. (2006). Perspectivas agroindustriales actuales de los oligofructosacáridos (FOS). Agronomía Mesoamericana, 17, 265-86.

Chambert R, Treboul G, Dedonder R. (1974). Kinetic studies of Levansucrase of Bacillus subtilis. Eur J Biochem, 41, 285-300.

Charalampopoulos D, Rastall RA. (2012). Prebiotics in foods. Curr Opin Biotechnol, 23, 187-91.

Chen J, Chen X, Xu X, et al. (2011). Biochemical characterization of an intracellular 6G-fructofuranosidase from Xanthophyllomyces dendrorhous and its use in production of neo-fructooligosaccharides (neoFOSs). Bioresource Technol, 102, 1715-21.

Chien C-S, Lee W-C, Lin T-J. (2001). Immobilization of Aspergillus japonicus by entrapping cells in gluten for production of fructooligosaccharides. Enzyme Microbial Technol, 29, 252-7.

Cleveland J, Montville TJ, Nes IF, Chikindas ML. (2001). Bacteriocins: safe, natural antimicrobials for food preservation. Int $\mathrm{J}$ Food Microbiol, 71, 1-20.

Crittenden RG, Playne MJ. (1996). Production, properties and applications of food-grade oligosaccharides. Trends Food Sci \& Technol, 7, 353-61.
Csanadi Z, Sisak C. (2008). Production of short chain fructooligosaccharides. Hung, 1, 23-6.

Cummings JH, Macfarlane GT, Englyst HN. (2001). Prebiotic digestion and fermentation. Am J Clin Nutr, 73, 415s-20s.

Delzenne NM, Roberfroid MR. (1994). Physiological effects of nondigestible oligosaccharides. LWT - Food Sci Technol, 27, 1-6.

Dhake AB, Patil MB. (2007). Effect of substrate feeding on production of fructosyltransferase by Penicillium purpurogenum. Brazil $\mathrm{J}$ Microbiol, 38, 194-9.

Dominguez A, Rodrigues L, Lima N, Teixeira J. (2013). An overview of the recent developments on fructooligosaccharide production and applications. Food Bioprocess Technol, 7, 1-14.

Dorta C, Cruz R, Oliva-Neto P, Moura D. (2006). Sugarcane molasses and yeast powder used in the Fructooligosaccharides production by Aspergillus japonicus-FCL 119T and Aspergillus niger ATCC 20611. J Indus Microbiol Biotechnol, 33, 1003-09.

Englyst HN, Hudson GJ. (1996). The classification and measurement of dietary carbohydrates. Food Chem, 57, 15-21.

Farine S, Versluis C, Bonnici P, et al. (2001). Application of high performance anion exchange chromatography to study invertasecatalysed hydrolysis of sucrose and formation of intermediate fructan products. Appl Microbiol Biotechnol, 55, 55-60.

Fernandes P. (2010). Enzymes in food processing: a condensed overview on strategies for better biocatalysts. Enzyme Res, 2010, 1-19.

García-Casal MN. (2007). La alimentación del futuro: Nuevas tecnologías y su importancia en la nutrición de la población. Anales Venezolanos de Nutrición, 20, 108-14.

Ghazi I, De Segura AG, Fernández-Arrojo L, et al. (2005). Immobilisation of fructosyltransferase from Aspergillus aculeatus on epoxy-activated Sepabeads EC for the synthesis of fructo-oligosaccharides. J Mol Catal B: Enzymatic, 35, 19-27.

Ghazi I, Fernandez-Arrojo L, Garcia-Arellano H, et al. (2007). Purification and kinetic characterization of a fructosyltransferase from Aspergillus aculeatus. J Biotechnol, 128, 204-11.

Gibson G, Rastall R, eds. (2006). Prebiotics: development \& application. Chichester: Wiley.

Gibson GR. (1999). Dietary modulation of the human gut microflora using the prebiotics oligofructose and inulin. J Nutr, 129, 1438S-41S.

Gibson GR, Probert HM, Loo JV, et al. (2004). Dietary modulation of the human colonic microbiota: updating the concept of prebiotics. Nutr Res Rev, 17, 259-75.

Gibson GR, Roberfroid MB. (1995). Dietary modulation of the human colonic microbiota: introducing the concept of prebiotics. J Nutr, 125, 1401-12.

Gibson GR, Scott KP, Rastall RA, et al. (2010). Dietary prebiotics: current status and new definition. Food Sci Technol Bull: Funct Foods, 7, 1-19.

Graminha EBN, Gonçalves AZL, Pirota RDPB, et al. (2008). Enzyme production by solid-state fermentation: application to animal nutrition. Animal Feed Sci Technol, 144, 1-22.

Gutiérrez-Alonso P, Fernández-Arrojo L, Plou FJ, Fernández-lobato M. (2009). Biochemical characterization of a $\beta$-fructofuranosidase from Rhodotorula dairenensis with transfructosylating activity. FEMS Yeast Res, 9, 768-73.

Hang YD, Woodams EE, Jang KY. (1995). Enzymatic conversion of sucrose to kestose by fungal extracellular fructosyltransferase. Biotechnol Let, 17, 295-8.

Hayashi S, Hayashi T, Kinoshita J, et al. (1992). Immobilization of $\beta$-fructofuranosidase from Aureobasidium sp. ATCC 20524 on porous silica. J Indus Microbiol Biotechnol, 9, 247-50.

Hayashi S, Ito K, Nonoguchi M, et al. (1991). Immobilization of a fructosyl-transferring enzyme from Aureobasidium sp. on shirasu porous glass. J Ferment Bioeng, 72, 68-70.

Hayashi S, Matsuzaki K, Inomata Y, et al. (1993). Properties of Aspergillus japonicus $\beta$-fructofuranosidase immobilized on porous silica. World J Microbiol Biotechnol, 9, 216-20.

Hernalsteens S, Maugeri F. (2008). Purification and characterisation of a fructosyltransferase from Rhodotorula sp. Appl Microbiol Biotechnol, 79, 589-96.

Hölker U, Höfer M, Lenz J. (2004). Biotechnological advantages of laboratory-scale solid-state fermentation with fungi. Appl Microbiol Biotechnol, 64, 175-86.

Jung K, Bang S, Oh T, Park H. (2011). Industrial production of fructooligosaccharides by immobilized cells of Aureobasidium pullulans in a packed bed reactor. Biotechnol Lett, 33, 1621-4. 
Kaur N, Gupta A. (2002). Applications of inulin and oligofructose in health and nutrition. J Biosci, 27, 703-14.

Kilian S, Kritzinger S, Rycroft C, et al. (2002). The effects of the novel bifidogenic trisaccharide, neokestose, on the human colonic microbiota. World J Microbiol Biotechnol, 18, 637-44.

Kim M-H, In M-J, Cha HJ, Yoo YJ. (1996). An empirical rate equation for the fructooligosaccharide-producing reaction catalyzed by $\beta$-fructofuranosidase. J Ferment Bioeng, 82, 458-63.

Kurakake M, Ogawa K, Sugie M, et al. (2007). Two types of $\beta$-fructofuranosidases from Aspergillus oryzae KB. J Agricult Food Chem, 56, 591-6.

Lateef A, Gueguim Kana E. (2012). Utilization of cassava wastes in the production of fructosyltransferase by Rhizopus stolonifer LAU 07. Romanian Biotechnol Lett, 17, 7309-16.

Lateef A, Oloke J, Gueguim kana E, et al. (2008a). Rhizopus stolonifer LAU 07: a novel source of fructosyltransferase. Chem Papers, 62, 635-8.

Lateef A, Oloke J, Gueguim Kana E, et al. (2008b). Improving the quality of agro-wastes by solid-state fermentation: enhanced antioxidant activities and nutritional qualities. World J Microbiol Biotechnol, 24, 2369-74.

Lim J, Lee J, Kang S, et al. (2007). Studies on production and physical properties of neo-FOS produced by co-immobilized Penicillium citrinum and neo-fructosyltransferase. Eur Food Res Technol, 225, 457-62.

Lin TJ, Lee YC. (2008). High-content fructooligosaccharides production using two immobilized microorganisms in an internal-loop airlift bioreactor. J Chinese Inst Chem Eng, 39, 211-17.

Linde D, Rodríguez-Colinas B, Estévez M, et al. (2012). Analysis of neofructooligosaccharides production mediated by the extracellular $\beta$-fructofuranosidase from Xanthophyllomyces dendrorhous. Bioresource Technol, 109, 123-30.

Longo MA, Deive FJ, Domínguez A, Sanromán M. (2008). Solid-state fermentation for food and feed application. In: Pandey A, Soccol CR, Larroche $\mathrm{C}$, eds. Current developments in solid-state fermentation. New York: Springer, 379-411.

Macfarlane GT, Steed H, Macfarlane S. (2008). Bacterial metabolism and health-related effects of galacto-oligosaccharides and other prebiotics. J Appl Microbiol, 104, 305-44.

Macfarlane S, Macfarlane GT, Cummings JH. (2006). Review article: prebiotics in the gastrointestinal tract. Aliment Pharmacol Therapeut, $24,701-14$.

Madlová A, Antošová M, Baráthová M, et al. (2000). Biotransformation of sucrose to fructooligosaccharides: the choice of microorganisms and optimization of process conditions. In: Stanislaw Bielecki JT, Jacek P, eds. Progress in biotechnology. Zakopane, Poland: Elsevier, 151-155.

Maiorano A, Piccoli R, Da Silva E, De Andrade Rodrigues M. (2008a). Microbial production of fructosyltransferases for synthesis of prebiotics. Biotechnol Lett, 30, 1867-77.

Maiorano A, Piccoli R, Silva E, Andrade Rodrigues M. (2008b). Microbial production of fructosyltransferases for synthesis of prebiotics. Biotechnol Lett, 30, 1867-77.

Mateo C, Palomo JM, Fernandez-Lorente G, et al. (2007). Improvement of enzyme activity, stability and selectivity via immobilization techniques. Enzyme Microbial Technol, 40, 1451-63.

Monsan PF, Ouarné F. (2009). Oligosaccharides derived from sucrose prebiotics and probiotics science and technology. In: Charalampopoulos D, Rastall RA, eds. New York: Springer, 293-336.

Murphy O. (2001). Non-polyol low-digestible carbohydrates: food applications and functional benefits. Br J Nutr, 85(Suppl 1), S47-53.

Mussatto SI, Aguilar CN, Rodrigues LR, Teixeira JA. (2009a). Colonization of Aspergillus japonicus on synthetic materials and application to the production of fructooligosaccharides. Carbohydr Res, 344, 795-800.

Mussatto SI, Aguilar CN, Rodrigues LR, Teixeira JA. (2009b). Fructooligosaccharides and $\beta$-fructofuranosidase production by Aspergillus japonicus immobilized on lignocellulosic materials. J Mol Catal B: Enzymatic, 59, 76-81.

Mussatto SI, Mancilha IM. (2007). Non-digestible oligosaccharides: a review. Carbohydr Polym, 68, 587-97.

Mussatto SI, Prata MB, Rodrigues LR, Teixeira JA. (2012). Production of fructooligosaccharides and $\beta$-fructofuranosidase by batch and repeated batch fermentation with immobilized cells of Penicillium expansum. Eur Food Res Technol, 235, 13-22.

Nemukula A, Mutanda T, Wilhelmi BS, Whiteley CG. (2009). Response surface methodology: synthesis of short chain fructooligosaccharides with a fructosyltransferase from Aspergillus aculeatus. Bioresource Technol, 100, 2040-5.

Nomenclature I-IJCOB. (1982). Abbreviated terminology of oligosaccharide chains. J Biol Chem, 257, 433-437.

Olvera C, Castillo E, López-munguía A. (2007a). Fructosiltransferasas, fructanas y fructosa. Biotecnología, 327-345.

Olvera C, Centeno-leija S, López-munguía A. (2007b). Structural and functional features of fructansucrases present in Leuconostoc mesenteroides ATCC 8293. Antonie Van Leeuwenhoek, 92, 11-20.

Park M, Lim J, Kim J, et al. (2005). Continuous production of neofructooligosaccharides by immobilization of whole cells of Penicillium citrinum. Biotechnol Lett, 27, 127-30.

Park YK, Almeida MM. (1991). Production of fructooligosaccharides from sucrose by a transfructosylase from Aspergillus niger. World $\mathrm{J}$ Microbiol Biotechnol, 7, 331-4.

Pérez Conesa D, López Martínez G, Ros Berruezo G. (2004). Principales prebióticos y sus efectos en la alimentación humana. Murcia: Universidad de Murcia, Servicio de Publicaciones ed. Anales de veterinaria Murcia.

Pineiro M, Asp NG, Reid G, et al. (2008). FAO Technical meeting on prebiotics. J Clin Gastroenterol, 42(suppl 3 Pt 2):S156-9.

Plou Gasca FJ, Alcalde Galeote M, Ghazi I, et al. (2009). Efficient fructooligosaccharide synthesis with a fructosyltransferase from Aspergillus aculeatus. In: Fessner W-D, Anthonsen T, eds. Modern biocatalysis: stereoselective and environmentally friendly reactions. Wiley-VCH: John Wiley \& Sons, 153-171.

Prata M, Mussatto S, Rodrigues L, Teixeira J. (2010). Fructooligosaccharide production by Penicillium expansum. Biotechnol Lett, 32, 837-40.

Rastall RA, Maitin V. (2002). Prebiotics and synbiotics: towards the next generation. Curr Opin Biotechnol, 13, 490-6.

Reyed M. (2007). The role of bifidobacteria in health. Res J Med \& Med Sci, 2, 14-24.

Rivero-Urgell M, Santamaria-Orleans A. (2001). Oligosaccharides: application in infant food. Early Human Dev, 65(supplement 2), S43-52.

Roberfroid M, Slavin J. (2000). Nondigestible oligosaccharides. Crit Rev Food Sci Nutr, 40, 461-80.

Roberfroid MB. (1993). Dietary fiber, inulin, and oligofructose: a review comparing their physiological effects. Crit Rev Food Sci Nutr, 33, 103-48.

Roberfroid MB. (2007a). Prebiotics: the concept revisited. J Nutr, 137, 830S-7S.

Roberfroid MB. (2007b). Inulin-type fructans: functional food ingredients. J Nutr, 137, 2493S-502S

Roberfroid MB. (2002). Functional foods: concepts and application to inulin and oligofructose. Br J Nutr, 87, S139-43.

Roberfroid MB, Delzenne NM. (1998). Dietary fructans. Ann Rev Nutr, $18,117-43$.

Roberfroid MB, Van Loo JAE, Gibson GR. (1998). The bifidogenic nature of chicory inulin and its hydrolysis products. J Nutr, 128, $11-19$.

Rodríguez Couto S, Sanromán MA. (2005). Application of solid-state fermentation to ligninolytic enzyme production. Biochem Eng J, 22, 211-19.

Rustiguel CB, Oliveira AHCD, Terenzi HCF, et al. (2011). Biochemical properties of an extracellular ${ }^{2}$-D-fructofuranosidase II produced by Aspergillus phoenicis under solid-sate fermentation using soy bran as substrate. Electr J Biotechnol, 14, 1-10.

Sabater-Molina M, Larqué E, Torrella F, Zamora S. (2009). Dietary fructooligosaccharides and potential benefits on health. J Physiol Biochem, 65, 315-28.

Sánchez O, Guio F, Garcia D, et al. (2008). Fructooligosaccharides production by Aspergillus sp. N74 in a mechanically agitated airlift reactor. Food Bioproducts Proces, 86, 109-15.

Sánchez O, Rodriguez A, Silva E, Caicedo L. (2010). Sucrose biotransformation to fructooligosaccharides by Aspergillus sp. N74 free cells. Food Bioprocess Technol, 3, 662-73.

Sangeetha PT, Ramesh MN, Prapulla SG. (2004). Production of fructosyl transferase by Aspergillus oryzae CFR 202 in solid-state fermentation using agricultural by-products. Appl Microbiol Biotechnol, 65, 530-7. 
Sangeetha PT, Ramesh MN, Prapulla SG. (2005). Fructooligosaccharide production using fructosyl transferase obtained from recycling culture of Aspergillus oryzae CFR 202. Process Biochem, 40, 1085-8.

Sarbini SR, Rastall RA. (2011). Prebiotics: metabolism, structure, and function. Funct Food Rev, 3, 93-106.

Sarmiento Rubiano LA. (2006). Alimentos funcionales, una nueva alternativa de alimentación. Orinoquia, 10, 16-23.

Scheid MMA, Moreno YMF, Maróstica Junior MR, Pastore GM. (2013). Effect of prebiotics on the health of the elderly. Food Res Int, 53, 426-32.

Sheldon RA. (2007). Enzyme immobilization: the quest for optimum performance. Adv Synth Catal, 349, 1289-307.

Sheu D, Chang J, Wang C, et al. (2013). Continuous production of high-purity fructooligosaccharides and ethanol by immobilized Aspergillus japonicus and Pichia heimii. Bioprocess Biosyst Eng, 36, 1745-1751.

Silveira Rodríguez MB, Monereo Megías S, Molina Baena B. (2003). Alimentos funcionales y nutrición óptima: ¿Cerca o lejos? Revista Española de Salud Pública, 77, 317-31.

Slavin J. (2013). Fiber and prebiotics: mechanisms and health benefits. Nutrients, 5, 1417-35.

Tanriseven A, Aslan Y. (2005). Immobilization of Pectinex Ultra SP-L to produce fructooligosaccharides. Enzyme Microbial Technol, 36, $550-4$.

Tomotani EJ, Vitolo M. (2007). Production of high-fructose syrup using immobilized invertase in a membrane reactor. J Food Eng, 80, $662-7$.
Vega R, Zuniga-Hansen ME. (2014). A new mechanism and kinetic model for the enzymatic synthesis of short-chain fructooligosaccharides from sucrose. Biochem Eng J, 82, 158-65.

Venter CS. (2007). Prebiotics: an update. J Fam Ecol Consum Sci, 35, $17-25$.

Wallis GLF, Hemming FW, Peberdy JF. (1997). Secretion of two $\beta$-fructofuranosidases by Aspergillus niger growing in sucrose. Arch Biochem Biophys, 345, 214-22.

Walton G, Swann J, Gibson G. (2013). Prebiotics. In: Rosenberg E, Delong E, Lory S, Stackebrandt E, Thompson F, eds. The prokaryotes. Berlin Heidelberg: Springer, 25-43.

Wang L-M, Zhou H-M. (2006). Isolation and identification of a novel Aspergillus japonicus JN19 producing $\beta$-fructofuranosidase and characterization of the enzyme. J Food Biochem, 30, 641-58.

Watzl B, Girrbach S, Roller M. (2005). Inulin, oligofructose and immunomodulation. Br J Nutr, 93, S49-55.

Yoshikawa J, Amachi S, Shinoyama H, Fujii T. (2008). Production of fructooligosaccharides by crude enzyme preparations of $\beta$-fructofuranosidase from Aureobasidium pullulans. Biotechnol Lett, 30, 535-9.

Yun J, Jung K, Oh J, Lee J. (1990). Semibatch production of fructooligosaccharides from sucrose by immobilized cells of Aureobasidium pullulans. Appl Biochem Biotechnol, 24-25, 299-308.

Yun J, Song S. (1996). Continuous production of fructooligosaccharides using fructosyltransferase immobilized on ion exchange resin. Biotechnol Bioprocess Eng, 1, 18-21.

Yun JW. (1996). Fructooligosaccharides-occurrence, preparation, and application. Enzyme Microb Technol, 19, 107-17. 